\title{
Herbivory In a SPATIALly Heterogeneous ENVIRONMENT - PIKAS OCHOTONA PRINCEPS AND High ALPINE Vegetation
}

\author{
JON MOEN $\downarrow$ DEPARTMENT OF ECOLOGICAL BOTANY \\ UMEå UNIVERSITY $\downarrow$ SWEDEN \\ TARJA OKSANEN $\downarrow$ DEPARTMENT OF ANIMAL ECOLOGY \\ UMEả UNIVERSITY $\downarrow$ SWEDEN
NANCY HUNTLY $\downarrow$ DEPARTMENT OF BIOLOGICAL SCIENCES IDAHO STATE UNIVERSITY $\downarrow$ POCATELLO

\section{$\downarrow \quad$ INTRODUCTION}

Landscape ecology has been very influential in developing tools for describing both structure (e.g. the distribution and sizes of patches) and function (i.e. the flow among patches) of heterogeneous environments (Turner 1989, Turner \& Gardner 1991). This approach has shown that spatial heterogeneity on a landscape level may influence many types of ecological processes (Kolasa \& Pickett 1991, Wiens et al. 1993). However, it is also clear that landscape structure and function must be described from an organism-centered view (Kolasa \& Pickett 1991), which invites the use of population dynamic hypotheses, and presents the challenging task of merging population ecology with landscape ecology.

Standard, non-spatial, predator-prey models predict that the grazing pressure in a given area is related to primary productivity (Oksanen et al. 1981). The model assumes that the number of dynamically important trophic levels is dependent on primary productivity and, in its simplest form, it can be outlined as follows: In extremely unproductive areas (e.g. boulder-fields), plant biomass is too low to sustain mammalian herbivores. In undisturbed areas, plants will thus eventually deplete their resources and compete. In moderately productive areas (e.g. arctic and alpine heaths), plant production is high enough to sustain herbivores, albeit at low densities, lower than what is needed for efficient predators to have a positive growth rate. Uncontrolled by predation, these herbivores are predicted to exert a strong grazing pressure on the vegetation. In more productive areas (e.g. tall herb meadows), plant production is high enough to sustain both herbivores and predators. With herbivores controlled by predation, plants will experience a low grazing pressure, and competition will be an important structuring factor for the plants. According to these models, a productivity gradient from extremely barren areas to productive areas should contain a zone of strong grazing pressure at intermediate productivities. A reanalysis using two types of patches with different primary productivity (T. Oksanen 1990) shows that the exact predictions depend on the proportion of these two patches in the habitat. Predation pressure could be high (and thus grazing pressure low) in a patch of intermediate productivity if it is embedded in a matrix of more productive patches, and, reversely, a productive patch might have a high grazing pressure if it is embedded in a matrix of less 
productive patches. These predictions parallel those of the source-sink model of Pulliam (1988) where a habitat where the consumer has a high growth rate "exports" juveniles to a habitat where the consumer growth rate is lower or even negative, thus creating a higher grazing pressure in the latter habitat than would have been possible without this continuous restocking of individuals.

The general conclusion from these models is that grazing pressure may vary between patches both as a consequence of differences in productivity and also because of the spatial arrangements of patches. Any comprehensive understanding of the interactions between herbivores and plants in a heterogeneous environment must thus be based on experiments and observations that explicitly take the spatial heterogeneity of the study area into account.

\section{$\uparrow \quad$ AIM \\ The aim of this project is to study population dynamics and grazing effects of a mammalian herbivore living in a patchy and heterogeneous environment to elucidate spatial variations in these processes.}

\section{STUDY SYSTEM}

The vegetation in high alpine areas in the Rocky Mountains is generally patchy. The patches are of different size, shape and productivity depending on edaphic differences, and they thus fit well with the situation described above. One of the main mammalian herbivores is the pika Ochotona princeps which inhabits talus and isolated rock piles in high altitudes. The pikas are active all year round and feed from meadows surrounding the talus (Huntly et al. 1986). They are diurnal and both males and females are strongly territorial with an average territory size of c. $500 \mathrm{~m}^{2}$ (Smith \& Ivins 1986), long-lived (>5 years; Smith 1987), and the populations are remarkably stable between years (Smith 1987). The foraging behavior of the pikas can best be described as central place foraging (Huntly et al. 1986, Orians \& Pearson 1979), i.e. costs associated with foraging (e.g. travel time or predation risk) increases with distance from talus. The pikas also construct hay piles which help to sustain them during the winter (Conner 1983). These hay piles can be weighed and the plant species composition in them can be determined. The patchy vegetation in high altitudes in the Rockies, together with the territoriality and haying of the pikas, make this an ideal system for studying spatially explicit herbivory.

\section{FIELD WORK IN 1994}

The field work for 1994 has been concentrated to Cody Bowl, Rendezvous Mt, Grand Tetons. Cody Bowl is a glacial cirque of about $1000 \times 600 \mathrm{~m}$ on an average altitude of $300 \mathrm{~m}$ a.s.1. The geology of the area is mainly sandstone and fossiliferous limestone. The vegetation is dominated by prostrate forbs and grasses, but more productive vegetation patches are also found.

A preliminary vegetation map of Cody Bowl has been made to make it possible to study herbivore movements and effects of herbivory on a landscape scale. Multispectral videography on three wavelengths, $650 \mathrm{~nm}$ (red), $750 \mathrm{~nm}$ (NIR), and 8-12 $\mu \mathrm{m}$ (thermal), was collected using low-level, fixed wing flights at $328 \mathrm{~m}$ above ground level. This flight altitude gives an average pixel resolution of $0.5 \mathrm{~m}^{2}$. The imagery was georeferenced and mosaicked in order to stitch sequential images together to form one large image. The different wavelengths were then used to classify the image using a maximum likelihood classifier into various cover-type signatures. Figure 1 shows a 180 by 90 $\mathrm{m}$ portion of the vegetation map.

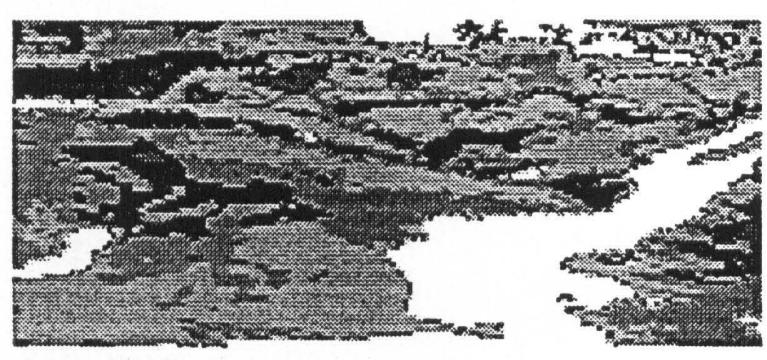

Figure 1. A portion $(180 \times 90 \mathrm{~m})$ of the vegetation map from Cody Bowl. Whwite is snow, dark grey and black are vegetation patches, and lighter grey shades are the stony matrix.

An image analysis software (Optimas) was then used to extract information of the spatial size and distribution of vegetation patches. Figure 2 shows the frequency distribution of vegetation patches in Figure 1. The data shows that the 
majority of vegetation patches are below $5 \mathrm{~m}^{2}$ in size, and that only a few are large enough to hold a territory of one or more pikas. Biomass samples from representative vegetation patches have also been collected and will be used in conjunction with the vegetation map to calculate amount of food available to the pikas.

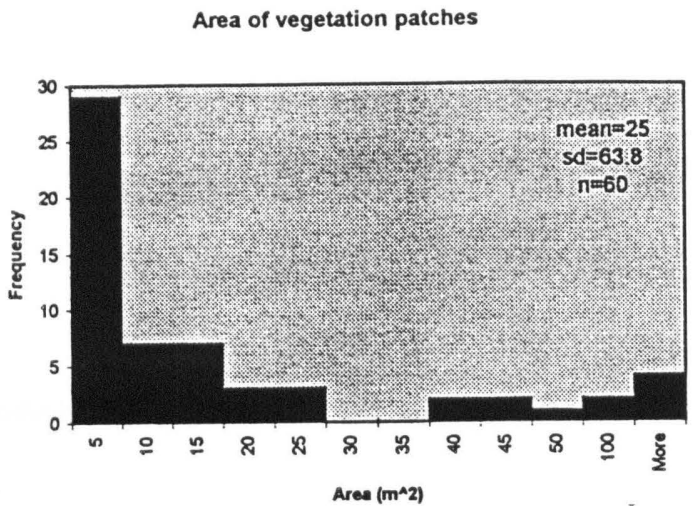

Figure 2. Distribution of sizes of vegetation patches from the image in Fig. 1.

Soil samples for analyses of nutrients (esp. nitrogen) was collected from hay pile sites and compared with soil samples from the matrix between hay piles. Plants growing on hay piles and in the matrix were also collected for nutrient analyses. The data have not yet been analyzed.

\section{THE FUTURE}

Funds have been applied for to continue the project for at least a three-year period. The work will then concentrate on refining the vegetation map, determining territory sizes and animal movements, and studying grazing effects on the plant communities.

\section{ACKNOWLEDGEMENTS}

We would like to thank the Jackson Hole Ski Corporation for generously providing tram transport during the summer. We would also like to thank Ken Aho, Catherine Pickering, Joe Sirotnak, Kyle Merriam and Dan Lawson for help with the field work. This project was supported by the Fulbright Commission, the Swedish-American Foundation, the Swedish Natural Research Council and the Kempe Foundation.

\section{Literature CITED}

Conner, D.A. 1983. Seasonal changes in activity patterns and the adaptive significance of haying in pikas Ochotona princeps. Can. J. Zool. 61:411-416.

Huntly, N.J., A.T. Smith and B.L. Ivins. 1986. Foraging behavior of a refuging herbivore, the pika Ochotona princeps: Lagomorpha, with comparisons of grazing and caching. J. Mamm. 67:139-148.

Kolasa, J. and S.T.A. Pickett. 1991. Ecological Heterogeneity. Springer, NY.

Oksanen, T. 1990. Exploitation ecosystems in heterogeneous habitat complexes. Evo. Ecol. 4:220-234。

Oksanen, L., S.D. Fretwell, J. Arruda and P. Niemelä. 1981. Exploitation ecosystems in gradients of primary productivity. Am. Nat. 118:240-261.

Orians, G.H. and N.E. Pearson. 1979. On the theory of central place foraging. In: Horn, D.J., Stairs, G.R. and Mitchell, R.D. (eds). Analysis of Ecological Systems. Ohio State Univ. Press, Columbus. pp. 155-177.

Pulliam, H.R. 1988. Sources, sinks, and population regulation. Am. Nat. 132:652661.

Smith, A.T. and B.L. Ivins. 1986. Territorial intrusions by pikas as a function of occupant activity. Anim. Behav. 34:392397.

Smith, A.T. 1987. Population structure of pikas: dispersal versus philopatry. In: ChepkoSade, B.D. and Halpin, Z.T. (eds). Mammalian Dispersal Patterns. Univ. of Chicago Press, Chicago. pp. 128-142.

Turner, M.G. 1989. Landscape ecology: the effect of pattern on process. Ann. Rev. Ecol. Syst. 20:171-197. 
Turner, M.G. and R.H. Gardner. 1991. Quantitative Methods I Landscape Ecology: the Analysis and Interpretation of Landscape Heterogeneity. Springer, NY.

Wiens, J.A., N.C. Stenseth, B. Van Horne, and R.A. Ims. 1993. Ecological mechanisms and landscape ecology. Oikos 66:369-380. 